\title{
PENDEKATAN SISTEM KELUARGA TERHADAP \\ KONFLIK DI DALAM GEREJA DAN RETORIKA \\ PAULUS DALAM SURAT FILEMON
}

\author{
Brury Eko Saputra \\ Melisa Mewani Lassa
}

\begin{abstract}
Abstraksi: Artikel ini berusaha membaca retorika Paulus dalam suratnya kepada Filemon dalam terang Pendekatan Sistem Keluarga terhadap konflik. Penulis akan mengidentifikasi elemen rumah tangga (household), baik secara kultural maupun tekstual, dalam surat Filemon. Setelah itu, penulis akan menelaah penggunaan retorika Paulus dalam relasinya dengan Pendekatan Sistem Keluarga terhadap konflik.
\end{abstract}

Kata-kata Kunci: Konflik gereja, Paulus dan Konflik, Kekristenan Mula-mula dan Konflik

Abstract: This article attempts to read Paul's rhetoric in his letter to Philemon in light of Family System Approach to conflict. In doing so, the article will firstly identify the familial (household) elements, both culturally and textually, found in the letter of Philemon. It will then examine Paul's use of rhetorical devices in connection with the Family System Approach to the conflict in the letter.

Keywords: Church Conflict, Paul and Conflict, Early Chriatianity and Conflict 


\section{Surat Filemon dan Struktur Keluarga di Abad Pertama}

Berbeda dari zaman sekarang, masyarakat di abad pertama melihat komposisi sebuah keluarga tidak hanya dalam relasi suami-istri dan orang tua-anak. ${ }^{1}$ Berdasarkan informasi dari Aristoteles, masyarakat kuno menganggap budak sebagai bagian yang sangat penting dari sebuah rumah tangga (household). ${ }^{2}$ Eksistensi budak sebagai instrumen tuannya dalam mewujudnyatakan kehendak tuannya adalah integral dalam rumah tangga kuno, ${ }^{3}$ termasuk dalam aspek ekonomi. ${ }^{4}$ Pentingnya budak di abad pertama, khususnya dalam rumah tangga aristokratik Romawi, juga terlihat dalam penelitian Lindsay Peener. Di dalam artikelnya, Gender, Household Structure and Slavery, menunjukkan bahwa kehadiran budak dalam rumah tangga Romawi tidak terhindarkan, meskipun terdapat perbedaan daya asimilasi setiap budak dalam tiap keluarga. ${ }^{5}$ Hal ini menyebabkan pemerintah

\footnotetext{
${ }^{1}$ Margaret Y. MacDonald, "Kinship and Family in the New Testament World", in Dietmar Neufeld and Richard E. DeMaris, eds.,Understanding the Social World of the New Testament (New York: Routledge, 2010), 30; bdk. Heach O'Brien mengingatkan setiap pembaca surat Filemon untuk waspada terhadap perbedaan realita sosial abad pertama yang tampak dalam surat ini. Realita tersebut asing dari era masa kini, sehingga pembaca masa kini tidak boleh gegabah dalam memutuskan strategi pembacaan terhadap teks tersebut. Lih. Amanda Heach dan Shawn O'Brien, "Paul Pleads with Philemon: Paul as the Master Mediator", in Conflict Management and The Apostle Paul (Eugene: Cascade, 2018), 51.

${ }^{2}$ Aristotle, Politics, I.2, 1252ab9

${ }^{3}$ Aristotle, Politics, I.2, 1252a31; bdk. Carolyn Osiek dan David L. Balch, Families in the New Testament World Households and House Churches (Louisville: Westminster John Knox, 1997), 75

${ }^{4}$ S. S. Bartchy, "Slavery (Greco-Roman)", in D.N. Freedman, ed., ABD Vol.6 (New York: Doubleday, 1992b), 69.

${ }^{5}$ Lindsay Penner, "Gender, Household Structure and Slavery: Re-Interpreting the Aristocratic Columbaria of Early Imperial Rome", in Ray Laurence and Agneta Strömberg, eds., Families in the Greco-Roman World (New York: Continuum International Publishing Group, 2012), 146-51.
} 
Roma mengakomodir kehadiran budak dalam rumah tangga melalui hukum mereka. ${ }^{6}$ Dengan adanya data tersebut, maka pembaca surat Filemon harus hati-hati dalam memberikan penilaian tentang relasi antara Filemon dan Onesimus. ${ }^{7}$ Relasi mereka tidak seperti relasi yang dimiliki oleh majikan dan hamba di masa sekarang. Relasi yang dimiliki keduanya harus dibaca dalam konteks keluarga (household) abad pertama. ${ }^{8}$

Pembenaran lain bagi pembacaan Pendekatan Sistem Keluarga terhadap konflik dalam teks Perjanjian Baru juga dikarenakan kekristenan mula-mula tetap menggunakan sistem keluarga (household) seperti itu. ${ }^{9}$ Osiek dan Balch menunjukkan bahwa sistem keluarga di abad pertama, yang juga melibatkan budak di dalamnya, dapat dengan mudah ditemukan dalam suratsurat Paulus dan empat Injil. ${ }^{10}$ Selain itu, secara teologis, komunitas Kristen mula-mula kerap kali mengidentifikasi keterlibatan mereka di dalam komunitas sebagai interaksi yang

${ }^{6}$ J. A. Harril, "Paul and Slavery," in J.P Sampley, ed., Paul in Greco-Roman World (London: Bloomsbury Publishing, 2016), 576.

${ }^{7}$ N. T. Wright, di dalam bagian awal bukunya, menunjukkan bahwa fenomena yang tejadi dalam surat Filemon adalah hal yang kerap terjadi di abad pertama. Dengan kasus yang cukup mirip tercatat dalam surat Pliny sebagaimana dikutip oleh Wright. Lih. N. T. Wright, Paul and the Faitfulness of God (Minneapolis: Fortress, 2013), 3-7, 22-7.

${ }^{8}$ Lih. Osiek dan Balch, Families in the New Testament, 174.

${ }^{9}$ Penelitian David deSilva menunjukkan bahwa kekristenan mula-mula melakukan modifikasi terhadap sistem kekeluargaan Greco-Roman di abad pertama supaya sesuai dengan konteks mereka. Hal tersebut membuktikan bahwa kekristenan mula-mula tetap menggunakan sistem kekeluargaan yang lazim saat itu, meskipun dengan penyesuaisan teologis dan struktural. Lih. David A. deSilva, "Re-writing 'Household' in the Early Church", in Ashland Theological Journal (2014), 85-94.

${ }^{10}$ Osiek dan Balch, Families in the New Testament, 174-92. 
bersifat kekeluargaan-mereka adalah bagian dari keluarga Allah. ${ }^{11}$ John Barclay mencatat bahwa komunitas Kristen mula-mula justru memberikan identitas, sebagai bagian keluarga Allah, bagi petobat baru di tengah hostilitas keluarga biologis mereka terhadap iman baru mereka. $^{12}$

Data di atas membuka peluang bagi penafsir surat Filemon ${ }^{13}$ di masa kini untuk membaca surat tersebut sebagai upaya menyelesaikan suatu konflik dalam konteks keluarga-konflik antara Filemon (tuan) dan Onesimus (budak). Dalam artikel ini, penulis berupaya membaca retorika Paulus dengan kerangka Pendekatan Sistem Keluarga terhadap Konflik. Penulis akan terlebih dahulu memaparkan secara singkat Pendekatan Sistem Keluarga terhadap konflik. Setelah itu, penulis akan mencoba menelisik retorika dalam Paulus dalam surat Filemon dalam kerangka pendekatan tersebut.

\section{Pendekatan Sistem Keluarga dalam Penanganan Konflik}

Dalam buku Church Conflict: The Hidden Systems Behind the Fights, Charles H. Cosgrove dan Dennis D. Hatfield berpendapat bahwa di balik sistem pemerintahan apapun yang

${ }^{11}$ Halvor Moxnes, ed., Constructing Early Christian Families: Family as Social Reality and Metaphor (New York: Routledge, 1997); Wright berpendapat bahwa kesatuan yang dimungkinkan karena kehadiran Kristus di dalam komunitas tersebut. Lih. Wright, Paul and the Faitfulness, 16-22.

12 John Barclay, "The Family as the Bearer Religion in Judaism and Early Christianity", in Halvor Moxnes, ed., Constructing Early Christian Families: Family as Social Reality and Metaphor (New York: Routledge, 1997), 73-5. ${ }^{13}$ Untuk sejarah penafsiran surat Filemon, lih. Demetrius K. Williams, "No Longer as a Slave: Reading the Interpretation History of Paul's Epistle to Philemon", in Matthew V. Johnson, et. al., eds., Onesimus Our Brother: Reading Religion, Race, and Culture in Philemon (Minneapolis: Fortress Press, 2012), 11-45. 
dianutnya, sistem kekeluargaan tetap dapat ditemukan di dalamnya. ${ }^{14}$ Menurut mereka, di dalam menerapkan pendekatan ini bagi konflik gereja, ada dua hal penting yang harus diperhatikan. Pertama, perlu adanya identifikasi terhadap struktur kekuasaan di dalam gereja tersebut. Pendamping penyelesaian konflik perlu mengenal pihak mana yang berperan sebagai orang tua-pihak yang berotoritas-dan pihak mana yang berperan sebagai anak-pihak yang dependen/bergantung. ${ }^{15}$ Hal kedua yang perlu diperhatikan adalah bagaimana family rules dan implementasinya dalam gereja tersebut. $^{16}$ Poin kedua ini berhubungan erat dengan kualitas komunikasi antara anggota keluarga di dalam gereja tersebut. ${ }^{17}$

Lauren Visser dan Greg Mamula meringkas pendekatan ini dan cara penerapannya dengan sangat baik dalam artikel mereka $A n$ Introduction to Modern Conflict Management. ${ }^{18}$ Visser dan Mamula menyimpulkan bahwa ada empat fakta yang patut dicermati dalam menangani konflik di gereja (kongregasional). Pertama, sistem kongregasional (gereja) menghubungkan setiap anggota; kedua, sistem tersebut dinamis tapi pada saat yang bersamaan juga stabil; ketiga, sistem keluarga dalam gereja mendorong kepekaan untuk peduli pada sesama anggotanya; dan keempat, kehidupan psikis (psychic life) seorang anggota jemaat tidaklah bersifat private tetapi terhubung dengan anggota lainnya. ${ }^{19}$ Di dalam menerapkan pendekatan ini secara kontekstual, ada beberapa strategi yang dapat dipilih. Pertama, bertindak dari dalam

\footnotetext{
${ }^{14}$ Charles H. Cosgrove and Dennis D. Hatfield, Church Conflict: The Hidden Systems Behind the Fights (Nashville: Abingdon Press, 1994), 5.

${ }^{15}$ Cosgrove and Hatfield, Church Conflict, chs. 2-3.

${ }^{16}$ Cosgrove and Hatfield, Church Conflict, chs. 4.

${ }^{17}$ Bdk. Cosgrove and Hatfield, Church Conflict, 33.

${ }^{18}$ Lauren Visser and Greg Mamula, "An Introduction to Modern Conflict Management," in Scot McKnight and Greg Mamula, eds., Conflict Management and the Apostle Paul (Eugene: Cascade, 2018), xviii-xx.

${ }^{19}$ Visser and Mamula, "An Introduction," xx.
} 
komunitas untuk menghasilkan perubahan; kedua, fokus pada akar masalah dan faktor penyebabnya; ketiga, berusaha mendekatkan jarak kedua belah pihak akibat dari konflik; dan keempat, membentuk koalisi baru dalam komunitas untuk mengeliminasi konflik yang telah terbentuk. ${ }^{20}$

\section{Pendekatan Sistem Keluarga terhadap Konflik dan Retorika Paulus}

Paulus memulai surat ini (ayat 1-3) dengan keterangan yang jelas bahwa surat ini bukan hanya untuk Filemon saja, tetapi juga untuk Apfia, Arkhipus, dan terlebih kepada jemaat yang ada di rumah Filemon (ayat 1-2). Dengan kata lain, Paulus melihat persoalan yang terjadi antara Onesimus dan Filemon sebagai persoalan dalam komunitas yang lebih luas-jemaat di rumah Filemon. Dalam hal ini jelas bahwa, bagi Paulus, persoalan antara Onesimus dan Filemon bukanlah persoalan personal tetapi persoalan dalam konteks keluarga. $^{21}$ Menariknya, Paulus mendorong masalah ini tidak lagi dipandang sebagai persoalan keluarga sebagaimana lazimnya hukum keluarga (household code) di abad pertama, di mana seorang tuan memiliki hak penuh atas budak yang ada dalam rumah tangganya. Paulus mendorong agar persoalan antara Onesimus dan Filemon dipandang sebagai persoalan dalam keluarga Allah. ${ }^{22}$

\section{Exordium: ayat 4-7}

Secara retoris, ayat 4-7 dapat dikelompokkan sebagai bagian exordium. Hal menarik dari exordium di bagian ini adalah rujukan

\footnotetext{
${ }^{20}$ Visser and Mamula, "An Introduction," xx.

${ }^{21}$ Bdk. David E. Garland, Colossians/Philemon - The NIV Application Commentary (Grand Rapids: Zondervand, 1998), 318.

${ }^{22}$ Bdk. Osiek dan Balch, Families in the New Testament, 174-8.
} 
terhadap "kasih Filemon" dalam ayat 5 dan ayat 7. David W. Pao mengatakan "kasih" tersebut adalah fokus Paulus di bagian ini, karena ekspresi tersebut membuka jalan bagi permohonan Paulus tentang persoalan Onesmius (ayat 9). ${ }^{23}$ Dengan kata lain, kasih yang telah Filemon tunjukkan kepada orang kudus (ayat 5, 7) juga dapat dinyatakan kepada Onesimus. ${ }^{24}$ Joseph A. Fitzmyer berpendapat bahwa strategi retorika seperti ini bersifat deliberatif, di mana doa Paulus diharapkan menjadi dorongan yang kuat bagi Filemon untuk meneruskan kasihnya kepada orang kudus (ayat 7), termasuk kepada Onesimus (ayat 9). ${ }^{25}$ Hal ini tentu saja sejalan dengan konsep bahwa kumpulan orang percaya adalah keluarga. Sama seperti Filemon menunjukkan kasihnya kepada orang kudus yang adalah anggota keluarganya di dalam Tuhan, ia juga harus dapat menunjukkan hal tersebut kepada Onesimus yang pada saat itu telah menjadi Kristen (bagian dari keluarga Allah).

\section{Main Body: ayat 8-16}

Ayat 8 dimulai dengan kata $\delta$ ió (karena itu) sebagai penanda peralihan antara bagian exordium ke main body. Pada saat yang bersamaan, secara retoris, kata $\delta$ ió juga berfungsi untuk menunjukkan strategi retorika Paulus dalam menyatakan permohonannya kepada Filemon. Dalam ayat 8 jelas bahwa Paulus mengungkapkan bahwa di dalam Kristus ia memiliki kebebasan untuk "memerintah" Filemon. Berdasarkan kerangka Pendekatan Sistem Keluarga terhadap konflik, posisi Paulus di sini adalah sebagai orang tua yang memiliki kuasa atas anaknya. Dalam relasi

\footnotetext{
${ }^{23}$ David W. Pao, Colossians and Philemon-Zondervan Exegetical Commentary on the New Testament (Grand Rapids: Zondervan, 2012), 369.

${ }^{24}$ Pao, Colossians and Philemon, 369.

25 Joseph A. Fitzmyer, The Letter to Philemon-The Anchor Bible, Vol.34C (New York, NY: Doubleday, 2000), 25-28; bdk. Church, "Rhetorical Stucture And Design in Paul's Letter to Philemon", HTR 71, 22-4.
} 
semacam itu, Filemon seharusnya memiliki kewajiban untuk melayani Paulus (bdk. ayat 13) karena keberadaan Filemon sebagai anggota keluarga (Kristen) diperoleh dari Paulus (bdk. ayat 19). ${ }^{26}$ Meskipun memiliki kebebasan sebagai orang tua, Paulus tidak menggunakan wewenang tersebut dengan semena-mena; ia memilih untuk meminta Filemon untuk menunjukkan kasihnya kepada Paulus-orang tua di dalam iman (ayat 9; bdk. ayat 4, 7). ${ }^{27}$

Strategi retorika Paulus juga dapat ditemukan dengan membandingkan ayat 8-9a dan 9b-10a.

\begin{tabular}{|l|l|}
\hline \multicolumn{1}{|c|}{ Ayat 8-9a } & \multicolumn{1}{c|}{ Ayat 9b-10a } \\
\hline $\begin{array}{l}\text { Karena itu, sekalipun di } \\
\text { dalam Kristus aku }\end{array}$ & Aku, Paulus, seorang Rasul \\
mempunyai kebebasan penuh & Kristus dan terlebih lagi \\
untuk memerintahkan & sekarang dipenjarakan karena \\
kepadamu apa yang harus & Kristus Yesus, mengajukan \\
engkau lakukan, tetapi & permohonan kepadamu \\
mengingat kasihmu itu, lebih & mengenai anakku yang \\
baik aku memintanya dari & peranakan selagi aku di dalam \\
padamu. & penjara, yakni Onesimus. \\
\hline
\end{tabular}

Berdasarkan tautologi di atas pembaca dapat menemukan bahwa Paulus sedang menunjukkan perannya yang superior dibandingkan Filemon, namun pada saat bersamaan juga menunjukkan bahwa superioritas tersebut dapat ditanggalkan dalam menyelesaikan persoalan dalam konteks keluarga. Paulus lebih memilih memberikan teladan kerendahan hati kepada Filemon dan

\footnotetext{
${ }^{26}$ Elemen etos dan pathos dalam ilmu retorika sangat jelas dalam bagian ini. Bandingkan penjelasan Aristoteles tentang kedua elemen retoris tersebut: Aristotle, The Art of Rhetoric, 1.3.1

${ }^{27}$ Lih. Douglas J. Moo, The Letters to the Colossians and to Philemon (Grand Rapids, Michigan: William B. Eerdmans, 2008), 401.
} 
memberikan kesempatan kepada Filemon dalam memutuskan persoalan ini. ${ }^{28}$ Dengan memberikan teladan seperti itu, Paulus sedang mendekati persoalan antara Onesimus dan Filemon sebagai seorang insider yang mengusahakan perubahan di tengah konflik yang terjadi.

Referensi terhadap sistem keluarga kembali muncul dalam ayat 10 ketika Paulus menyebut Onesimus sebagai anaknya. Rujukan terhadap Onesimus sebagai anak (rohani) Paulus membuat dorongan yang lebih kuat bagi Filemon untuk menerima Onesimus lebih dari seorang budak, tetapi sebagai seorang saudara (bdk. ayat 16; Kol. 4:9). ${ }^{29}$ Dalam hal ini pembaca dapat menemukan bahwa dalam setiap penggunaan rhetorical device di surat ini, Paulus sedang menempatkan persoalan ini dalam sebuah sistem keluarga. Paulus, sebagai orang tua, sedang mendamaikan keduanya anaknya yang sedang berkonflik. Berdasarkan teori sistem keluarga dalam menangani konflik, apa yang Paulus lakukan ini dapat dipandang sebagai usaha untuk mendekatkan kedua belah pihak-anggota keluarga-yang sedang bertikai, sehingga persoalan dapat diatasi dengan lebih baik. ${ }^{30}$

Dalam ayat 12-13 Paulus kembali menggunakan strategi retoris dalam sistem kekeluargaan di mana ia menekankan tanggung jawab seorang anak terhadap orang tuanya. Sebagai seorang anak rohani, Filemon seharusnya memiliki kewajiban untuk melayani Paulus, terutama di masa-masa sulitnya (bdk. ayat 13). Peran Filemon sebagai anak digantikan oleh Onesimus, buah hati Paulus (bdk. ayat 12), untuk menunjukkan bahwa dalam

\footnotetext{
${ }^{28}$ Bdk. Church, “Rhetorical Stucture And Design in Paul's Letter to Philemon”, HTR 71, 25.

${ }^{29}$ Douglas J. Moo, The Letters to the Colossians and to Philemon-The Pillar New Testament Commentary (Grand Rapids: William B. Eerdmans, 2008), 422. ${ }^{30}$ Lih. Visser and Mamula, "An Introduction," xx.
} 
keluarga Allah keduanya adalah sama-terikat sebagai saudara. ${ }^{31}$ Menariknya, meskipun Paulus memainkan peran sebagai orang tua, ia tidak melupakan dimensi (atau realita) sosial bahwa menurut pandangan masyarakat umum Onesimus tetap adalah seorang budak. Untuk dapat mempertemukan dimensi sosial dan teologis dalam konteks keluarga ini, sebagai orang tua, Paulus menggunakan bahasa yang bersifat mendelegasikan wewenangnya sebagai orang tua kepada Filemon (bdk. ayat 14). ${ }^{32}$

Upgrade terhadap status Onesimus dari seorang budak menjadi saudara dalam konteks keluarga tidak hanya melalui pengangkatan Onesimus sebagai anak (rohani) Paulus, tetapi juga melalui penerimaan Filemon (ayat 16) ${ }^{33}$ Penerimaan ini membuat

${ }^{31}$ Marchal berpendapat bahwa rujukan terhadap peran Onesimus dalam ayat 11 dan 13 dapat baca sebagai peran seorang budak secara seksual dalam dunia Greco-Roman. Memang, banyak sekali budak di era tersebut menjalankan fungsi seksual untuk memuaskan tuannya. Namun, dalam konteks surat Filemon, pembaca akan sulit menghubungkan kesetaraan peran Onesimus bagi Paulus dan rujukan terhadap peran tersebut seharusnya dilakukan oleh Filemon dalam ayat 13. Lih. Joseph A. Marchal, "The Usefulness of an Onesimus: The Sexual Use of Slaves and Paul's Letter to Philemon", in Journal of Biblical Literature, Vol. 130, No. 4 (2011): 749-770.

${ }^{32}$ Pembacaan yang menempatkan Onesimus dan Filemon dalam kesetaraan dalam konteks keluarga seperti ini menawarkan strategi pembacaan (postkolonial) yang lebih natural terhadap teks daripada pembacaan dengan motif politis sepeti dalam Sung Uk Lim, "The Otherness of Onesimus: Re-reading Paul's Letter to Philemon from the Margins", in Theology Today Vol. 73.3 (2016): 215-229.

${ }^{33}$ Ada ahli seperti Allen Callahan yang berpendapat bahwa Onesimus dan Filemon memang adalah saudara. Degradasi status Onesimus menjadi budak diakibatkan kesalahan Onesimus terhadap Filemon. Pendapat tersebut sangat menarik, hanya saja tidak didukung dengan data yang komprehensif, khususnya dalam kekristenan mula-mula. Lih. Allen Callahan, Embassy of Onesimus: The Letter of Paul to Philemon (Edinburgh: Trinity Press International, 1997), 50; bdk. Moo, The Letters to the Colossians and to Philemon, 366-9; untuk ulasan tentang penggunaan kata $\alpha \dot{\delta} \varepsilon \lambda \varphi \varsigma_{\varsigma}$ dalam konteks kekristenan mula-mula, lih. 
relasi anak-budak dalam keluarga menjadi anak-anak (saudara). James Dunn menyatakan bahwa penerimaan Filemon terhadap Onesimus memang tidak mengubah kebergantungan Onesimus pada Filemon secara sosial maupun finansial, namun demikian, penerimaan ini memberikan perasaan hangat dalam sebuah keluarga kepada keduanya. ${ }^{34}$ Meskipun tidak mengaitkan surat Filemon dengan keluarga di abad pertama, Garland memberikan sebuah gambaran yang sangat baik tentang status baru Onesimus. Menurut Garland, harapan Paulus supaya Filemon menerima Onesimus dapat digambarkan seperti harapan ayah dari anak yang hilang dalam Lukas 15:11-32. Di dalam narasi Lukas 15:11-32 terlihat bahwa sang ayah memiliki harapan agar si sulung dapat menerima si bungsu sebagai seorang saudara. ${ }^{35}$ Retorika Paulus dalam mendorong Filemon untuk menerima Onesimus sebagai saudara dapat dipahami sebagai usaha membentuk koalisi (kategori) baru dalam perspektif Pendekatan Sistem Keluarga dalam menangani konflik. ${ }^{36}$

\section{Peroration: ayat 17-22}

Dalam bagian peroration, Paulus menekankan kembali permohonannya melalui dua buah kalimat bersyarat: 1) ayat 17: kalau engkau menganggap aku temanmu seiman, terimalah dia seperti aku sendiri; dan 2) ayat 18: kalau dia sudah merugikan engkau ataupun berhutang padamu, tanggungkanlah semuanya itu kepadaku. Kedua kalimat bersyarat tersebut memiliki muatan retorika yang sangat kuat di mana Paulus melibatkan dirinya

Paul Trebilco, Self-Designations and Group Identity in the New Testament (Cambridge: Cambridge University Press, 2012), 16-67.

${ }^{34}$ James Dunn, The Epistle to the Colossians and to Philemon-The New International Greek Testament Commentary (Grand Rapids: William B.

Eerdmans, 1996), 336.

${ }^{35}$ Garland, Colossians/Philemon, 328.

${ }^{36}$ Bdk. Visser and Mamula, “An Introduction,” xx. 
sendiri baik secara positif (dengan menerima Onesimus seperti menerima Paulus) maupun negatif (dengan menanggung "hutang" Onesimus) dalam konteks keluarga. Michael F. Bird memberikan komentar yang sangat penting tentang kedua kalimat bersyarat ini:

This debt of Philemon to Paul was probably incurred during Philemon's coming to faith. Maybe Paul even 'begat' Philemon in much the same way that he has begat Onesimus; in which case Philemon and Onesimus are brothers through having the same spiritual father. ${ }^{37}$

Komentar Bird memberikan indikasi bahwa dasar bagi Paulus untuk dapat menyatakan permohonan melalui dua buah kalimat bersyarat tersebut adalah karena relasi Paulus sebagai bapa spiritua bagi Filemon dan Onesimus. Dengan dasar yang sama pula Paulus memiliki keyakinan bahwa Filemon akan melakukan lebih dari yang Paulus minta (bdk. ayat 21).

\section{Surat Filemon dan Konflik dalam Gereja Masa Kini}

Berdasarkaan telaah retorika yang Paulus gunakan dalam surat Filemon dengan Pendekatan Sistem Keluarga terhadap konflik di atas, maka dapat disimpulkan bahwa seruan untuk rekonsiliasi di dalam surat ini tidak terbatas hanya pada budak dengan tuan, tetapi juga gereja lokal atau jemaat. Nicholas dan Wintle menegaskan hal tersebut dengan mengungkapkan bahwa gereja lokal yang adalah komunitas orang-orang merupakan sebuah keluarga. ${ }^{38}$ Identitas keluarga tersebut terlihat dari persekutuan (koinonia) yang aktif dan bersifat timbal balik antar anggotanya. ${ }^{39}$

\footnotetext{
${ }^{37}$ Michael F. Bird, Colossians \& Philemon-New Covenant Commentary Series (Cambridge: The Lutherworth Press, 2009), 142.

${ }^{38}$ Nicholls \& Wintle, Colossians and Philemon: A Pastoral and Contextual Commentary (Cumbria: Langham Global Library, 2019), 203.

${ }^{39}$ Nicholls \& Wintle, Colossians \& Philemon, 203.
} 
Sama seperti kekristenan mula-mula di abad pertama, gereja masa kini juga adalah sebuah keluarga, sehingga perlu juga mempertimbangkan penyelesaian konflik dengan kerangka sistem keluarga.

Tentu saja, persoalan atau konflik gereja di zaman teknologi sekarang ini tidak sama dengan gereja di abad pertama. Kendati pun demikian, tetap ada prinsip yang dapat dihayati dari persoalan gereja di rumah Filemon bagi gereja hari ini. Secara esensial, anggota jemaat perlu menyadari kenyataan bahwa setiap jemaat adalah anggota keluarga Allah; sebagai koalisi baru yang melampaui persoalan dalam konflik. Dengan kesadaran tersebut, setiap anggota jemaat yang terlibat dalam persoalan harus mengedepankan kepentingan keluarga Allah di atas kepentingan individu. $^{40}$ Upaya-upaya penyelesaian konflik harus dengan pertimbangan greater dan common good serta kemuliaan Allah. Selain itu, setiap langkah harus didasarkan pada kasih terhadap sesama anggota keluarga Allah (bdk. Filemon 5, 7, 9). Hal lainnya, jemaat dapat berusaha mengidentifikasi peran dalam keluarga tersebut. Siapakah yang memainkan peran sebagai orang tua dan anak dalam gereja tersebut. Umumnya, pejabat atau tua-tua gereja memainkan peran sebagai orang tua. Dalam kondisi normal, orang tua dapat menjadi pemersatu bagi jemaat yang memainkan peran sebagai anak. ${ }^{41}$ Namun, dalam kondisi tertentu, orang tua dapat mendelegasikan "peran" mereka kepada anak, sehingga mereka dapat bertanggungjawab atas keputusan yang diambil (bdk. Filemon 8, 10, 14).

Bagian ini hanyalah memberikan masukan-masukan bagi gereja masa kini berdasarkan pembacaan Pendekatan Sistem Keluarga terhadap konflik atas retorika Paulus dalam surat

\footnotetext{
${ }^{40}$ Bdk. Heach dan O'Brien, "Paul Pleads with Philemon”, 34-5.

${ }^{41}$ Bdk. Heach dan O'Brien, "Paul Pleads with Philemon", 36-7.
} 
Filemon. Oleh karena itu, bagian ini lebih bersifat deskriptif daripada preskriptif. Meskipun demikian, masukan-masukan yang diberikan bersifat umum dan prinsipil, sehingga memberikan kekeluasaan bagi setiap pembaca mendapatkan keuntungannya darinya.

\section{DAFTAR RUJUKAN}

Aristotle. Politics. Oxford: Oxford University Press, 2009.

Aristotle. The Art of Rhetoric. Ed. Lawson-Tancred, Hugh. London: Penguin Classics, 1992.

Barclay, John "The Family as the Bearer Religion in Judaism and Early Christianity", in Halvor Moxnes ed. Constructing Early Christian Families: Family as Social Reality and Metaphor. New York: Routledge, 1997.

Bartchy, S. S. "Slavery (Greco-Roman)", in D.N. Freedman, ed. $A B D$ Vol.6. New York: Doubleday, 1992.

Bird, Michael F. Colossians \& Philemon-New Covenant Commentary Series. Cambridge: The Lutherworth Press, 2009.

Callahan, Allen. Embassy of Onesimus: The Letter of Paul to Philemon. Edinburgh: Trinity Press International, 1997.

Church, "Rhetorical Stucture And Design in Paul's Letter to Philemon", in HTR 71.

Cosgrove, Charles H. Hatfield, Dennis D. Church Conflict: The Hidden Systems Behind the Fights. Nashville: Abingdon Press, 1994. 
deSilva, David A. "Re-writing 'Household' in the Early Church", in Ashland Theological Journal, 2014.

Dunn, James The Epistle to the Colossians and to Philemon-The New International Greek Testament Commentary. Grand Rapids: William B. Eerdmans, 1996.

Fitzmyer, Joseph A. The Letter to Philemon-The Anchor Bible, Vol.34C. New York, NY: Doubleday, 2000.

Garland, David E. Colossians/Philemon-The NIV Application Commentary. Grand Rapids: Zondervand, 1998.

Harril, J. A. "Paul and Slavery", in J.P Sampley, ed. Paul in GrecoRoman World. London: Bloomsbury Publishing, 2016.

Heach, Amanda. O'Brien, Shawn. "Paul Pleads with Philemon: Paul as the Master Mediator", in Scot McKnight, et. al., eds. Conflict Management and The Apostle Paul. Eugene: Cascade, 2018.

MacDonald, Margaret Y. "Kinship and Family in the New Testament World", in Dietmar Neufeld, et. al., eds. Understanding the Social World of the New Testament. New York: Routledge, 2010.

Marchal, Joseph A. "The Usefulness of an Onesimus: The Sexual Use of Slaves and Paul's Letter to Philemon", in Journal of Biblical Literature, Vol. 130, No. 4, 2011.

Moo, Douglas J. The Letters to the Colossians and to PhilemonThe Pillar New Testament Commentary. Grand Rapids: William B. Eerdmans, 2008.

Moxnes, Halvor. Constructing Early Christian Families: Family as Social Reality and Metaphor. New York: Routledge, 1997. 
Nicholls \& Wintle. Colossians and Philemon: A Pastoral and Contextual Commentary. Cumbria: Langham Global Library, 2019.

Osiek, Carolyn. Balch, David L. Families in the New Testament World Households and House Churches. Louisville: Westminster John Knox, 1997.

Pao, David W. Colossians and Philemon - Zondervan Exegetical Commentary on the New Testament. Grand Rapids: Zondervan, 2012.

Penner, Lindsay "Gender, Household Structure and Slavery: ReInterpreting the Aristocratic Columbaria of Early Imperial Rome", in Ray Laurence, et al., eds. Families in the GrecoRoman World. New York: Continuum International Publishing Group, 2012.

Sung Uk Lim, "The Otherness of Onesimus: Re-reading Paul's Letter to Philemon from the Margins", in Theology Today Vol. 73.3, 2016.

Trebilco, Paul. Self-Designations and Group Identity in the New Testament. Cambridge: Cambridge University Press, 2012.

Visser, Lauren. Mamula, Greg. "An Introduction to Modern Conflict Management", in Scot McKnight and Greg Mamula, eds. Conflict Management and the Apostle Paul. Eugene: Cascade, 2018.

Williams, Demetrius K. "No Longer as a Slave: Reading the Interpretation History of Paul's Epistle to Philemon", in Matthew V. Johnson, et. al., eds. Onesimus Our Brother: Reading Religion, Race, and Culture in Philemon. Minneapolis: Fortress Press, 2012. 